\title{
Bacteria Patterns on Tonsillar Surface and Tonsillar Core Tissue among Patients Scheduled for Tonsillectomy at Bugando Medical Centre
}

\section{Gustave Buname}

Catholic University of Health and Allied Sciences

\section{Gapto Kiwale}

Catholic University of Health and Allied Sciences

Vitus Silago

Catholic University of Health and Allied Sciences

Martha F Mushi ( $\square$ mushimartha@gmail.com )

Catholic University of Health and Allied Sciences

\section{Stephen E Mshana}

Catholic University of Health and Allied Sciences

\section{Research Article}

Keywords: Tonsillar, BMC, Core, Surface, Tonsillectomy

Posted Date: June 25th, 2021

DOI: https://doi.org/10.21203/rs.3.rs-640239/v1

License: (c) (i) This work is licensed under a Creative Commons Attribution 4.0 International License. Read Full License 


\section{Abstract}

Background: Tonsillitis is an inflammation of tonsils due to either viruses or bacteria. Here we report the bacteria patterns on tonsillar surface and tonsillar core tissue among patients scheduled for tonsillectomy at Bugando Medical Centre (BMC), Mwanza Tanzania.

Methods: The study included 120 patients planned for tonsillectomy between April and July 2019. Swab samples from tonsilar surface pre-tonsillectomy and core post-tonsillectomy were collected. Culture was performed following the microbiology laboratory standard operating procedures. Data analysis was done using STATA version 13 as per study objectives.

Results: The slightly majority of participants were males 73 (60.83\%) with median age of 6 [IQR 4-11] years. The proportion of culture positive growth was high on surface than in core swab samples $65(54.2 \%)$ vs $42(35.0 \%)$, $p=0.003$. The commonest bacterial pathogen detected from the surface and core were $S$. aureus $29(40.3 \%)$ and $22(51.2 \%)$, followed by S. pyogenes, $17(23.6 \%)$ and $11(25.6 \%)$, respectively. Features suggestive of tonsillitis on histology were reported in $83(73.5 \%)$ of samples.

Conclusion: More than two-third of patients undergoing tonsillectomy had positive culture of possible bacterial pathogens. Streptococcus pyogenes and Staphylococcus aureus were the predominant bacteria detected. More studies to investigate the treatment outcome of these patients are highly recommended.

\section{Introduction}

Tonsillectomy is one of the most frequently performed otolaryngological operation worldwide (1). Tonsillectomy can be performed at any age but is mainly performed among children $(2,3)$. It is indicated in patients with adenotonsillar hypertrophy, recurrent acute tonsillitis with at least five or more episode attaches attacks in a year, obstructive sleep apnea and peritonsillar abscess(4). Recurrent acute tonsillitis is mainly associated with bacterial and/or viral infection of the tonsillar crypts or parenchyma and is characterized by sore throat, fever, odynophagia, leukocytosis, with congested tonsils with or without enlargement and tender jugulodigastric lymph node. The tonsil infection may occur primarily or secondarily as a results of upper respiratory tract infections commonly preceded by viral infection(5).

Several pathogens have been implicated in tonsil infections including: Group A beta hemolytic Streptococcus, alpha hemolytic streptococcus, Hemophilus influenzae, Staphylococcus aureus, Enterococcus spp., Klebsiella pneumoniae, Brahmnella catarrhalis, Corynebacterium spp. and anaerobes like Peptostreptococci, Fusobacterium and Veillonella(6, 7). Neveretheless, previous studies conducted worldwide have reported the possibility of the tonsillar surface being colonized by the microbial flora which are not implicated in the tonsil infections $(8,9)$. The bacteria on the core of tonsil are highly associated with tonsilitis and are named to play vital role on the recurrent nature of the infections (10). Furthermore, the recurrent and chronic nature of the tonsilitis is highly associated with the ability of the implicated pathogen to resist the antibiotic therapy used. The antibiotic resistance is reported to be highly linked with the low concetration of antibiotic on the tonsilar core tissue caused by scarring as a result of recurent infections which impair the antibiotic diffusion $(5,11,12)$. Penicillin resistant among pharyngeal flora also account to the recurrent and chronic nature of tonslitis(13). In Tanzania, penicillin resistance is reported to range from 53-67.8\% among $S$. pneumoniae $(14,15)$ one of the leading cause of tonsilitis. The stead increase in resistance is reported to be associated with irrational use of antibiotic in the community (16). 
The significant complications of tonsillitis in resource limited settings is attributed to poor or lack of evidence based empiric antibiotic treatment guidelines due to lack of data from local studies (17). Recurrent tonsilitis pose a great health risk to patients including the post streptococcus (Rheumatic heart disease) diseases. The rheumatic heart diseases is beleaved to be more prevalent on resource limited settings like Tanzania(18). The effective treatment of recurrent tonsillitis highly depends on the ability of isolating the associated pathogen and its susceptibility pattern. The primary aim of this study was to determine patterns of gram positive bacteria on tonsillar surface pre tonsillectomy and tonsillar core tissue post tonsillectomy, among patients scheduled for tonsillectomy at Bugando Medical Centre (BMC), Mwanza Tanzania to obtain data to guide empirical treatment of tonsillitis.

\section{Results}

A total of 120 patients scheduled for tonsillectomy were recruited. The median age of studied patients was 6[IQR 411 years. Majority of studied patients were male $73(60.8 \%)$ and majority were from urban areas $98(81.7 \%)$. A total of 114 (95\%) studied patients had experienced breathing difficult and $60(50 \%)$ had fever. About a quarter $31(25.8 \%)$ of the studied patients had history of hospital admission and three quarter $90(75 \%)$ had history of antibiotic use due to tonsillitis, table 1.

Out of 90 patients with history of antibiotic use, 26(28.9\%) had self-prescription. A total of 29(24.2\%) patients were aware of antimicrobial resistance. More than one third of patients reported to have used penicillin 35(38.7\%), while macrolides was reported by more than one quarter $25(27.4 \%)$. A total of $10(11.3 \%)$ patients reported to have used traditional medicine for tonsillitis before tonsillectomy, Figure 1.

Recurrent tonsillitis was reported in 99(82.5\%) patients, table 1. The indication for tonsillectomy included; combination of obstructive sleep apnea, throat pain and swallowing difficult 82(68\%), a single reason of obstructive sleep apnea $28(23.3 \%)$, throat pain $8(6.7 \%)$ and swallowing difficult 2(1.7\%).

\section{Culture and susceptibility patterns}

A total of $86(71.7 \%)$ patients had positive culture growth of possible pathogenic bacteria on either tonsillar surface or tonsillar core. The proportion of culture positive growth was significant high on surface swab than in core swab samples $65(54.2 \%)$ vs $42(35.0 \%), p=0.003$. The prevalence of group A streptococcus (Streptococcus pyogenes) was found to be $14.2 \%(17 / 120)$.

In 65 surface swabs, there were 7 patients with dual bacteria growth making a total of 72 isolates. S. aureus $29(40.3 \%)$ followed by S. pyogenes $17(23.6 \%)$ were the most predominant possible pathogenic bacteria isolated on the tonsil surface, table 2 .

In 42 core swabs, there was one patient with dual bacteria growth making a total of 43 isolates. S. aureus 22(51.2\%) followed by $S$. pyogenes $12(27.9 \%)$ were the most predominant possible pathogenic bacteria isolated in the tonsil core, table 2.

S. pyogenes and S. pneumoniae were $100 \%$ sensitive to penicillin and vancomycin in all surface and core isolates.

\section{Histology results}

Histological examinations of the 120 tonsillar tissues indicated 83(69\%) to have features suggestive of tonsillitis. Seven (6\%) had features of reactive follicular tissue hyperplasia, figure 2. Of 83 tissues samples with suggestive features of tonsillitis, $71(85.5 \%)$ had positive growth of possible pathogenic bacteria. Significant high proportion of 
tissue with suggestive features of tonsillitis had positive growth of possible pathogenic bacteria on surface than on core $64(90.1 \%)$ vs $31(43.6 \%), p<0.001$. A total of $27(38.5 \%)$ had positive growth of possible pathogenic bacteria on both surface and core swabs.

Tonsillar tissue with features suggestive of tonsillitis in histological examinations had 4.8 odds of having culture positive results of possible pathogenic bacteria compare to tonsillar tissue without features suggestive of tonsillitis OR 4.8, 95\% Cl 2.0-11.2, $\mathrm{P}<0.001$.

\section{Discussion}

The local epidemiological data of bacteria in core and surface of the tonsils of patients clinically diagnosed to have tonsillitis are important in establishing proper empirical management protocol of these patients. In response to the call of the World Health Assembly in global action for combating RHD in 2018 this study has contributed by providing data on patterns of bacteria found on the surface and core of tonsil among patients scheduled for tonsillectomy. Nearly half of the patients in the current study were found to have possible pathogenic bacteria on the tonsillar surface. Which signify the importance of considering antibiotic treatment for patients with tonsillitis.

The findings from this study is significant different from the on reported from Iraq involving 73 children of the age range of 3-10 years which reported the prevalence of 58.9\% and India which reported the prevalence of 55\% (3). Furthermore, this prevalence is significant higher than $15.9 \%$ previous reported from a study conducted in Uganda (18). The broad range of possible pathogens reported in the current study could explain the difference. The study conducted in Uganda was centered on only group A Streptococcus sp. The prevalence of group A Streptococcus sp. Observed in the current study is similar to what was reported in Uganda.

The current study found the prevalence of possible pathogenic bacteria in tonsillar core to be $35.0 \%$. This prevalence is almost similar to $40.7 \%$ which was previously reported in India in a study which reported all possible pathogen in age group of 11-20 years(5). In addition, the current study prevalence is significant lower than the $90.4 \%$ previous reported from a study conducted in Iraq(3). The differences in nature of the sample use in these studies and geographical differences between study areas can explain the difference. The study in Iraq used fine needle aspiration while the current study used tonsil core swab. The fine needle aspirated have ability to concentrate the pathogen and increase the yield of the pathogen recovering in the tonsil. The fine needle aspiration culture is reported to have $100 \%$ sensitivity which is higher than $82.9 \%-92 \%$ sensitivity of the core swab culture $(19,20)$.

As previously reported elsewhere $(3,5,20)$, the current study found mixed growth of possible pathogenic bacteria in 7 tonsil surface swab and 1 core swab. The type of bacteria species in surface and core of the tonsil were similar in $22.1 \%$ of studied patients. This has also being reported from previous studies $(19,20)$.

Staphylococcus aureus and Streptococcus pyogenes were the predominant bacteria isolated on both tonsil surface and core. This has also being previous reported from other studies $(5,19)$. Only $62.1 \%$ and $59.1 \%$ of Staphylococcus aureus from the tonsil surface and core, respectively were sensitive to methicillin. This is hypothesized to be contributed by the chronicity nature of tonsillitis and presence of the scar on the tonsil which affect the amount of drug delivered to the core of the tonsil and contribute to the resistant observed. The similar resistance trend was reported in India (5).

\section{Limitation:}


Inability to perform anaerobic culture of bacteria and tissue culture for viruses might lead to under estimation of the reported prevalence. The use of patients scheduled for tonsillectomy limit the reproducibility of the study results to general population of patients with tonsillitis.

\section{Conclusion And Recommendation:}

More than two third of patients undergoing tonsillectomy at BMC had positive culture growth of possible pathogenic bacteria. Streptococcus pyogenes and Staphylococcus aureus were the predominant bacteria detected. More studies to investigate the treatment outcome of these patients are highly recommended.

\section{Methodology}

This prospective cross sectional hospital-based study was conducted among patients scheduled for tonsillectomy between April and July 2019. The study was conducted in the otolaryngology department of BMC, a tertiary teaching hospital of Catholic University of Health and Allied Health Sciences which has bed capacity of 1000 . The otolaryngology department of BMC performs about 70-80 tonsillectomies in a month. The minimum sample size was obtained using Kish Leslie formula (1965) using prevalence of $75 \%$ from a study conducted in India looking at the patterns of bacteria from patients with tonsillitis(17).

Patients were serially recruited to the study until the sample size was reached. The study excluded all patients with indication of tumor. Data (age, gender, employment status, and history of breath difficult, fever, swallowing difficult, hospital admission, dysphagia, antibiotic usage and recurrent tonsillitis etc.) were obtained using pre-coded structured questionnaire before the patient being under anesthesia.

In the current study recurrent tonsillitis was defined by having more than five episodes in a year(21). Tonsil core is the inner part of the tonsil include tonsil crypt reached by dissecting the tonsil tissue.

\section{Sample Collection and processing}

The surface of the tonsil was rubbed using sterile swab by the experienced surgeon while patient is under anesthesia. The tonsillectomy was conducted followed by the dissection of the tonsil to expose the core area and a second swab was taken immediately. All swabs were placed in the Stuart transport media and transported to microbiology laboratory for processing within two hours of collection.

In microbiology laboratory the swabs were inoculated on $5 \%$ sheep blood agar and chocolate agar. The plates were incubated in the candle jar for $18-24$ hours under $37^{\circ} \mathrm{C}$. The identification of bacteria species was based on their growth morphology, hemolytic patterns in blood agar and biochemical/physiological tests like catalase, coagulase, bile solubility test and their sensitivity patterns to bacitracin, optochin and trimethoprim/sulphamethoxazole.

\section{Data analysis}

Data were entered on excel spread sheet for consistent check and cleaning then transferred to STATA version 13 for analysis. Categorical data were summarized using proportions while continuous data were summarized using median and interquartile range. $P$ value of less than 0.05 at $95 \%$ confidence interval was considered statistically significant in the comparison of microbiological and histological results.

\section{Ethical considerations}


The protocol of this study was ethically approved by the CUHAS/BMC research ethics and review committee (CREC) with certificate number 912/2019. For participants in age below 18 years informed consent from a parent and/or legal guardian was obtained before recruitment. All the procedures were performed following the ethical guidelines.

\section{Declarations}

\section{Acknowledgements}

Authors would like to acknowledge the support provided by Department of ENT, Bugando Medical Centre / Weill Bugando School of Medicine, Catholic University of Health and Allied Sciences and the Department of Microbiology and immunology of the Catholic University of Health and Allied Sciences, Mwanza, Tanzania.

\section{Authors' contributions}

GB \& MFM designed the work. GB \& GAK recruited patients, GAK, VS and MFM performed laboratory investigations and results interpretations. MFM and SEM analyzed and interpreted the data. MFM wrote the first draft of the manuscript which was critically reviewed by SEM. All authors read and approved the final version of the manuscript.

\section{Consent for publication}

None applicable

\section{Availability of data and materials}

The datasets used and/or analyzed during the current study available from the corresponding author on reasonable request.

\section{Funding}

None

\section{References}

1. Ingram DG, Friedman NR. Toward adenotonsillectomy in children: a review for the general pediatrician. JAMA pediatrics. 2015;169(12):1155-61.

2. Gul M, Okur E, Ciragil P, Yildirim I, Aral M, Kilic MA. The comparison of tonsillar surface and core cultures in recurrent tonsillitis. American journal of otolaryngology. 2007;28(3):173-6.

3. Yousef RY, Yousef RY. Comparison of the bacteriology of tonsil surface and core in bacterial profile isolated from children with chronic tonsillitis. Medical Journal of Babylon. 2010;7(1-2):52-7.

4. Oburra $\mathrm{H}$, Idenya M. Frequency of adenotonsillectomy in some Nairobi hospitals. East African medical journal. 2001;78(7):338-42.

5. Agrawal A, Kumar D, Goyal A, Gupta R, Bhooshan S. Bacteriological evaluation and their antibiotic sensitivity pattern in tonsillitis. IOSR J Dental Med Sc. 2014;13(3):51-5.

6. Bista M, Sinha B, Amatya R, Tuladhar N, Pokharel B. Comparison of core and surface cultures in recurrent tonsillitis. J Institute Med. 2005;27:60-5.

7. Brook I, Yocum P, Shah K. Surface vs core-tonsillar aerobic and anaerobic flora in recurrent tonsillitis. Jama. 1980;244(15):1696-8. 
8. Bista M, Sinha B, Amatya R, Tuladhar N, Pokharel B. Comparison of core and surface cultures in recurrent tonsillitis. Journal of institute of medicine. 2007;27(3).

9. Kumai A, Gupta V, Chandra K, Gupta P, Varshney S. Clinico bacteriological evaluation of surface and core microflora in chronic tonsillitis. Indian Journal of Otolaryngology and Head and Neck Surgery. 2005;57(2):118.

10. Kurien M, Sheelan S, Jeyaseelan L, Thomas K. Fine needle aspiration in chronic tonsillitis: reliable and valid diagnostic test. The Journal of Laryngology \& Otology. 2003;117(12):973-5.

11. Loganathan A, Arumainathan U, Raman R. Comparative study of bacteriology in recurrent tonsillitis among children and adults. Singapore medical journal. 2006;47(4):271.

12. Kardooni M, Mosavian SM, Lotfınia M, Eghbalnejad AM, Mofrad MS, Saki N, et al. Study of common bacterial agents and antibiotic susceptibility in patients with chronic and repeated tonsillitis. Journal of Advanced Pharmacy Education \& Research| Apr-Jun. 2020;10(S2):91.

13. Hadi U, El-Hajj M, Uwaydah M, Fuleihan N, Matar GM. Characteristics of pathogens recovered from the tonsils and adenoids in a group of Lebanese children undergoing tonsillectomy and adenoidectomy. JOURNAL OF APPLIED RESEARCH IN CLINICAL AND EXPERIMENTAL THERAPEUTICS. 2005;5(3):473.

14. Moyo SJ, Steinbakk M, Aboud S, Mkopi N, Kasubi M, Blomberg B, et al. Penicillin resistance and serotype distribution of Streptococcus pneumoniae in nasopharyngeal carrier children under 5 years of age in Dar es Salaam, Tanzania. Journal of medical microbiology. 2012;61(7):952-9.

15. Emgård M, Msuya SE, Nyombi BM, Mosha D, Gonzales-Siles L, Nordén R, et al. Carriage of penicillin-nonsusceptible pneumococci among children in northern Tanzania in the 13-valent pneumococcal vaccine era. International Journal of Infectious Diseases. 2019;81:156-66.

16. Mboya EA, Sanga LA, Ngocho JS. Irrational use of antibiotics in the Moshi Municipality Northern Tanzania: a cross sectional study. The Pan African Medical Journal. 2018;31.

17. Vijayashree M, Viswanatha B, Sambamurthy B. Clinical and bacteriological study of acute tonsillitis. group. 2014;1(2):3.

18. DeWyer A, Scheel A, Webel AR, Longenecker CT, Kamarembo J, Aliku T, et al. Prevalence of group A $\beta$-hemolytic streptococcal throat carriage and prospective pilot surveillance of streptococcal sore throat in Ugandan school children. International Journal of Infectious Diseases. 2020;93:245-51.

19. Kurien M, Sheelan S, Jeyaseelan L, Kurien T. Fine needle aspiration in chronic tonsillitis: reliable and valid diagnostic test. The Journal of Laryngology and Otology. 2003;117(12):973.

20. Sarkar S, Sil A, Sarkar S, Sikder B. A comparison of tonsillar surface swabbing, fine-needle aspiration core sampling, and dissected tonsillar core biopsy culture in children with recurrent tonsillitis. Ear, Nose \& Throat Journal. 2017;96(6):E29-E32.

21. McKerrow WS. Recurrent tonsillitis. American family physician. 2002;66(9):1735.

\section{Tables}

\section{Table 1: Social demographic and clinical data of 120 studied patients}




\begin{tabular}{|c|c|c|}
\hline VARIABLE & MEDIAN/FREQUENCY & IQR /PERCENTAGE (\%) \\
\hline Age & 6 & 4-11 \\
\hline \multicolumn{3}{|l|}{ Sex } \\
\hline Male & 73 & 60.8 \\
\hline Female & 47 & 39.2 \\
\hline \multicolumn{3}{|l|}{ Location } \\
\hline Rural & 22 & 18.3 \\
\hline Urban & 98 & 81.7 \\
\hline \multicolumn{3}{|c|}{ Education level } \\
\hline Uneducated & 3 & 2.5 \\
\hline Primary & 19 & 15.8 \\
\hline Secondary & 52 & 43.3 \\
\hline University & 46 & 38.3 \\
\hline \multicolumn{3}{|c|}{ Breath difficult } \\
\hline Yes & 114 & 95.0 \\
\hline No & 6 & 5.0 \\
\hline \multicolumn{3}{|l|}{ Fever } \\
\hline Yes & 60 & 50.0 \\
\hline No & 60 & 50.0 \\
\hline \multicolumn{3}{|c|}{ Swallowing difficult } \\
\hline Yes & 91 & 75.8 \\
\hline No & 29 & 24.2 \\
\hline \multicolumn{3}{|c|}{ Infection history in family } \\
\hline Yes & 14 & 11.7 \\
\hline No & 106 & 88.3 \\
\hline \multicolumn{3}{|c|}{ If yes have been operated } \\
\hline Yes & 11 & 9.2 \\
\hline No & 109 & 90.8 \\
\hline \multicolumn{3}{|c|}{ History of hospital admission } \\
\hline Yes & 31 & 25.8 \\
\hline No & 89 & 74.2 \\
\hline Recurrent tor & & \\
\hline
\end{tabular}




\begin{tabular}{|lll|}
\hline Yes & 99 & 82.5 \\
\hline No & 21 & 17.5 \\
\hline Dysphagia & & 77.5 \\
\hline No & 93 & 22.5 \\
\hline Antibiotic usage & 27 & \\
\hline Yes & & 75.0 \\
\hline No & 90 & 25.0 \\
\hline Antibiotic usage decision & 30 & \\
\hline Health care worker & 64 & 71.1 \\
\hline Self & 26 & 28.9 \\
\hline Health care seeking & & \\
\hline On symptom insert & 64 & 24.8 \\
\hline Several days post infection & 32 & 26.7 \\
\hline After drug failure & 24 & 20.0 \\
\hline AMR awareness & 91 & \\
\hline Yes & 29 & \\
\hline No & & 24.8 \\
\hline Ear involvement & & \\
\hline Yes & & \\
\hline No & & \\
\hline
\end{tabular}

Table 2: Sensitivity patterns of gram-positive bacteria isolated from the surface and core tonsillar swab 


\begin{tabular}{|c|c|c|c|c|c|c|c|c|}
\hline Bacteria isolated & $E$ & DA & LZD & SXT & CIP & $\mathrm{CN}$ & AK & FOX \\
\hline \multicolumn{9}{|l|}{ Surface } \\
\hline S. aureus (29) & $14(48.3)$ & $18(62.1)$ & $4(13.8)$ & $5(17.2)$ & $15(51.7)$ & $18(62.1)$ & 23(79.3) & $18(62.1)$ \\
\hline S. pyogenes (17) & $11(64.7)$ & $12(70.6)$ & $10(58.8)$ & $0(0.0)$ & $11(64.7)$ & $14(82.4)$ & $14(82.4)$ & \\
\hline S. viridans (15) & 2(13.3) & 13(86.7) & 14(93.3) & 2(13.3) & 10(66.7) & 11(73.3) & $12(80)$ & \\
\hline S. pneumoniae (4) & $3(75)$ & $3(75)$ & $3(75)$ & $3(75)$ & $2(50)$ & $2(50)$ & $2(50)$ & \\
\hline $\begin{array}{l}\text { Enterococcous spp. } \\
\text { (3) }\end{array}$ & $2(66.7)$ & $2(66.7)$ & $2(66.7)$ & 1(33.3) & $3(100)$ & $3(100)$ & $2(66.7)$ & \\
\hline \multicolumn{9}{|l|}{ Core } \\
\hline S. aureus (22) & $9(40.9)$ & $12(54.5)$ & $12(54.5)$ & $8(36.4)$ & 13(59.1) & $14(63.6)$ & $15(68.2)$ & 13(59.1) \\
\hline S. pyogenes (12) & 11(91.7) & $6(50.0)$ & $9(75.0)$ & $0(0.0)$ & $8(66.7)$ & $9(75.0)$ & $9(75.0)$ & \\
\hline S. viridans (6) & $3(50.0)$ & $5(83.3)$ & $4(66.7)$ & $1(16.7)$ & $2(33.3)$ & $3(50.0)$ & $3(50.0)$ & \\
\hline
\end{tabular}

\section{Figures}

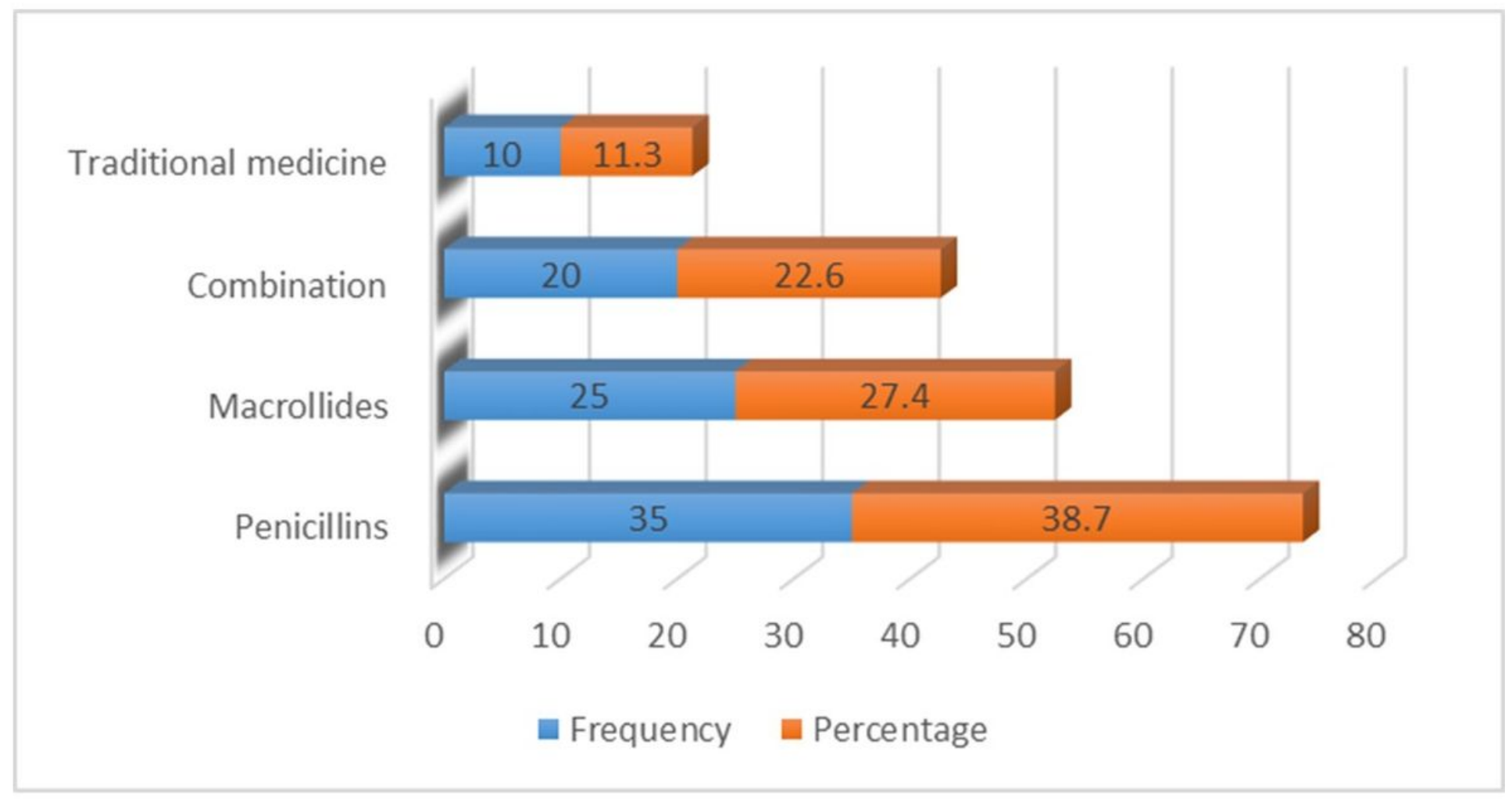

Figure 1

Type of medicine used before tonsillectomy 


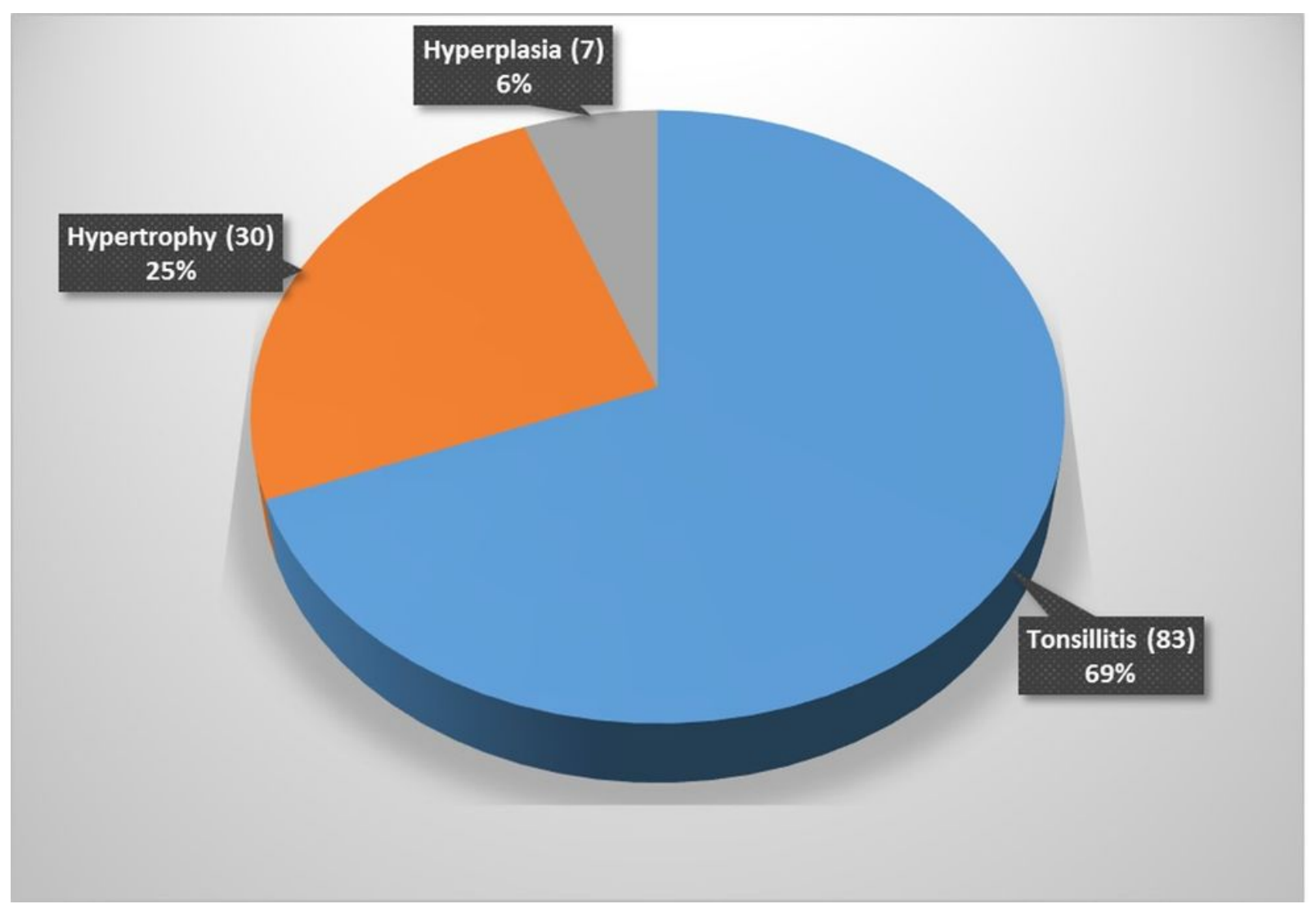

\section{Figure 2}

Histology results of tonsilar tissues 